\title{
Thinking and Measures of Fixed Assets Investment in Henan under the Background of Steady Growth and Trend
}

\author{
Bin $\mathrm{Li}$ \\ Department of Management \\ School of Business and Trade \\ Huanghe Science and Technology College \\ Zhengzhou, China
}

\begin{abstract}
Starting from the perspective of steady growth and trend of fixed assets investment in Henan province, this article conducts an analysis of the significance of fixed assets investment to the economic development in Henan, based on which, the status quo and problems relative to the fixed assets investment in the province are analyzed impersonally, and factors such as investment efficiency, financing channels and investment structure are deemed to have blocked the fixed assets investment in the province, furthermore, it shows the key fields for the fixed assets investment in the province during the 13th five-year plan period, and raises suggestions and measures to push the fixed assets investment in the province from developing major projects, continuously innovating financial mechanism, intensifying resource security, encouraging and instructing social investment as well as deepening investment system reform and so on, which can be borrowed for scientific decision making and used as references for the authorities concerned.
\end{abstract}

Keywords-fixed assets investment in Henan; steady growth and trend; basic thoughts

\section{INTRODUCTION}

Nowadays, the economic development in Henan has entered a New Normal stage featuring speed reduction, gear changes, structural adjustment, power change-over and quality and efficiency improvement, in face of this situation, in order to well arrange the relations between steady growth, structural adjustment and steady trend under the New Normal, it needs to persist in the investment pulling strategy, further carry out the state strategic layout, root in the fields specially supported by state and the construction of "one carrier, four systems and six foundations" to highlight the quality benefit, transformation and upgrade, innovative drive, living security and actively enlarge the investment needs, strive to increase the investment efficiency, and guarantee the investment efficiency and performance, so as to provide powerful support for the "steady growth, structural adjustment and steady trend" in Henan.

Project support: 2016 soft science project (Research on Problems Relative to Stabilizing Growth Rate and Adjusting Structure in Henan under the New Normal), project No: 162400410108.

\section{Status QUO OF FiXed AsSETS InVESTMENT IN HENAN}

In recent years, the investment pulling strategy has been continued in Henan, and with the investment scale enlarging, the investment speed begins to change gears and decelerate under the New Normal, the investment structure is further optimized and the investment has achieved an obvious economic growth.

\section{A. Investment Scale Continued in A Large Size}

Over the years, the investment scale which is increasing in Henan has played a key role in promoting the economic growth and the aftereffect development. Seen from the aggregate, in 2010, the fixed assets investment in the province totaled 1.65 trillion yuan, breaking through 3 trillion yuan in 2014, 1.8 times that in 2010, ranking 3 in the country. Seen from the proportion, in 2014, the proportion of fixed assets investment occupied $85.9 \%$ of the GDP, up 25.6 percent over 2010, and 6.9 percent higher than the average level of the country. In 2016, the fixed asses investment (excluding farmers) totaled 3975.393 billion yuan, up $13.7 \%$ over the previous year (excluding price, $14.6 \%$ actually), and the growth rate was 0.3 percent quicker than that in Jan-Nov.

\section{B. Investment Growth Gear Changes and Deceleration}

Since the international crisis taking place in 2008, Henan has changed its trend in the fixed assets investment, and the investment growth was adjusted to about $20 \%$ at a rapid growth range in 2011 from over 30\% at a high-speed growth range in 2008. After entering the New Normal, influenced by policy adjustment and market changes, the province further changed its growth of fixed assets investment. In 2013, its fixed assets investment increased by $23.2 \%$, up 3.6 percent over the average level of the country. In 2016, due to the factors such as slow industrial investment, decrease of real estate investment growth rate as well as the lack of new project starts, the investment growth rate took on a continuous decrease, increased by $13.7 \%$ in that year. 


\section{Investment Structure Optimized Unceasingly}

Seen from three industries, the proportion of investment in the tertiary industry was increasing. In 2011, the investment structure between three industries was 3.8: 53.9: 42.3, adjusted to 4.2: $51.3: 44.5$ in 2014, the proportion of investment in the secondary industry dropped by 2.6 percent, and the proportions of the investment in the primary industry and the tertiary industry increased by 2.2 percent and 0.4 percent respectively. Seen from the industrial structure, the high-growth industrial investment grew rapidly, whose proportion increased gradually. In 2012, the investments in six high-growth industries and high-tech industry in the province increased by $33.2 \%$ and $31.1 \%$, respectively, accounting for $65.3 \%$ and $4.3 \%$ in the industrial investment, up 5 and 0.3 percent respectively. In 2014, the investment in high-growth manufacturing in the province increased by $22.8 \%$, accounting for $54.2 \%$ of industrial investment, up 2.5 percent; the investment in the traditional pillar industry increased by $10.2 \%$, accounting for $36.2 \%$ of industrial investment, down 2.3 percentage. In 2016, among the industrial investments in the province, the investment in the high-growth manufacturing totaled 1001.871 billion yuan, up $7.5 \%, 1.4$ percent faster than that in Jan-Nov; the investment in the traditional pillar industry totaled 655.824 billion yuan, up $8.9 \%, 1.5$ percent faster than that in Jan- Nov.

\section{PROBLEMS EXISTING IN THE FIXED ASSETS INVESTMENT IN HENAN}

Nowadays, Henan has entered a New Normal stage, facing with new external environment and internal restriction, it has several problems existing relative to investment efficiency, structure and financing channels in the investment demand, which are urgent to solve.

\section{A. Investment Efficiency Needing Further Improvement}

In recent years, though the scale of fixed assets investment in Henan has been expanding yet, the investment effect has been declining. Generally the investment efficiency can be measured by the investment effect coefficient, that is, the ratio between new GDP in the report stage and the fixed assets investment of the same period. During 2011-2014, the investment effect coefficient was $0.223,0.128,0.101,0.093$ respectively, declining year by year, that is, in 2011, 1 yuan investment could form 0.223 yuan in GDP, yet 0.093 yuan in GDP in 2014, which means that currently it will need more investment to form the same in GDP.

\section{B. High Proportion of Investment Remained in Traditional Industries}

In the past years, though the proportion of investment in the high-growth manufacturing among the industrial investments has been increased gradually, yet the total investment of the province in energy, raw materials and so on is still larger. In 2016, the proportions of investment in energy and raw materials such as steel, nonferrous metals, petrochemical, building materials, electric power, heat and coal in the industrial investment and the province's investment were $29.6 \%$ and $15.2 \%$ respectively. And the proportions of investment in traditional industries such as food, textile and light industry in the industry and the province's investment were $22.3 \%$ and $11.4 \%$. respectively.

\section{Comparatively Narrow Financing Channels}

Though the diversification in financing in Henan has been strengthened, yet the status quo of a single channel for financing has not been fundamentally changed. In 2014, the actual investment of the province totaled 3016.28 billion yuan, including self-financing of 2302.68 billion yuan, accounting for $76.3 \%$ of the financing; domestic loan of 399.56 billion yuan, accounting for $13.2 \%$ of the financing. In 2016, the actual investment of the province totaled 3911.32 billion yuan, up $12.2 \%$, and 0.1 percent faster than that in Jan-Nov. Among it, the national budget funds increased by $5.5 \%$, down 4.5 percent in the growth rate; domestic loans decreased by $0.2 \%$, the growth rate was changed to positive from negative; the self-financing increased by $13.4 \%$, up 0.5 percent in the grow rate; the use of foreign investment increased by $27.4 \%$, down 3.5 percent in the growth rate; other funds increased by $24.4 \%$, up 0.3 percent in the growth rate. The self-financing has been main source channel for investment funds, and the financing (including loans, stocks, bonds, etc.) in finance was less than $20 \%$, of which, bank loans occupied a vast majority, and the direct financing ratio was very low. In addition, due to the blocking to convert social funds into investment funds as well as a low efficiency, though the overall social funds are adequate, yet in practice, the funds for construction are still inadequate.

\section{KEY FIELDS FOR FIXED ASSETS INVESTMENT IN HENAN}

During the 13th five-year plan period, the situation that the fixed assets investment in Henan becomes more complicated, and the industries in the east have accelerated steps to move toward the middle and west regions. The central one belt one road strategy is advanced much faster, accompanied with the rapid development of emerging industries due to the technical revolution, Henan has entered a crucial stage for structural upgrade and development transformation, the people's government and the provincial Party committee have established the strategic outlines of building a prosperous society and accelerating the modern construction, expanding the space for investment increase and doing good to the efficient investment in the province. In the meantime, due to the decelerating economic growth, industrial structure adjustment, development power shift, as well as large investment base, extensive growth and restricted resources and environments in the province, during the 13th five-year plan period, it is thought hard to continue the raid growth as it does now. Accordingly faced with the steady growth and trend, the fixed assets investment in the province shall be focused on the following in the coming years.

\section{A. Shift Powers and Intensify Investment in the Innovation- Driven Strategy}

The New Normal of economy means that innovation will be a main drive for the economic growth, under the situation, in order to achieve the steady growth, Henan needs to increase its investment in innovation filed and incubate drives to support the economic growth in the future. Step I: strengthen 
the construction of innovation system, root in strategic emerging industries, new \& hi-tech industry in the province, fully promote the investment in key field innovation, enrich and perfect the innovation carrying platforms, carry out openended innovation, promote the S\&T-based innovation in all aspects, build a modern innovation system and drive the development via innovation. Step II, value strategic "soft investment": the soft investment means that start with software such as basic research, technical standard, intellectual property right and so on, root in innovative industries such as strategic emerging industries, advanced manufacturing, knowledge intensive service, intensify investment in strategic emerging industries, technical equipment of manufacturing, innovative infrastructure and the like, so as to offer innovative drives for the construction of "three-big provinces".

\section{B. Solidify Foundations and Intensify the Investment in Technical Equipment for Upgrade}

For a long time, the investment in manufacturing in Henan has been focused on capacity expansion, and the technical renovation and upgrade are poor, and the investment growth is kept at the low speed, occupying a low proportion. In 2014, the investment in rebuilding and technical reform in the province increased by $9.5 \%, 25.9$ percent and 4.8 percent respectively less than the previous year and the average level of the country in 2014 , accounting for $4.4 \%$ of the total investment in the province, 0.3 percent and 9.1 percent respectively less than the previous year and the average level of the country in 2014. It means that the investment in technical renovation and upgrade will be in a great need in the future, which are basic conditions for the solid foundation, transformation and upgrade of manufacturing. Thus under the New Normal, it needs to root in high-growth manufacturing, strategic emerging industries, traditional backbone industries in the province, intensify the investment strength in manufacturing and technical equipment upgrade, incubate a manufacturing industrial system with perfect, sizable and complete industrial chains in support of the construction of a province large in manufacturing.

\section{Make Up Short Slabs and Increase Investment in Crucial Infrastructure}

Under the New Normal, the infrastructure is one of the key fields to expand the investment demand and stabilize the economic growth in Henan, and it is suggested to adhere to the key points, make up short slabs, improve the weakness and upgrade as a whole. Root in building a nationwide modern integrated transportation hub, center on the traffic grids and integrated hub construction, strengthen the five-infrastructure construction as transportation, information, water conservancy, energy and ecological environment, and constantly enhance the basic security and cultivate new advantages in regional competition. Step I: On traffic, center on building a modern integrated transport system, speed up the construction of largescale aviation hub of Zhengzhou, vigorously promote the "Star"-shaped railway network construction, and further improve the road network, push the inland water transport construction, and strength the efficient linking between highway, railway, aviation and water transport. Step II. On water conservancy, continue the governance on Huaihe River and Yellow River, speed up major flood control projects and the backbone river way management and improve the support and security relative to water resources. III. On energy and information infrastructure, continue to build nationwide important regional integrated energy bases and create a safe, stable, economical and clean modern energy industry system.

\section{Expand Spaces and Increase Investment in the New-Type Urbanization}

Increase the investment in the construction of new-type urbanization, new villages, and urban and rural integration demonstration areas, set up a modern urban system where the Central Plains urban agglomeration is the main form with a coordinated development of large, medium and small cities, towns and new villages so as to promote urban and rural development. Step I. root in upgrading the urban comprehensive service, strengthen the urban and rural infrastructure construction, improve the Zhengzhou Airport comprehensive economic pilot area, industrial cluster, commercial center area, featured commercial areas and so on so as to accelerate the new urbanization. Step II. On the municipal infrastructure, root in the ecological livable city construction, improve the living environment, speed up the urban river way environment governance, municipal roadwiden rebuilding, rail transportation, pipelines construction. III. On the rural infrastructure, govern the rural living environment, strengthen the construction of village infrastructures and public service facilities, and comprehensively improve the rural production and living conditions. Major projects include construction of beautiful villages, relocation of residents at the Yellow River Beach area and so on.

\section{SUGGESTIONS FOR EXPANDING THE FIXED ASSETS INVESTMENT IN HENAN}

\section{A. Push Major Projects in Order}

Major projects are important carriers for expanding investment. According to the projects' affiliation, set up a system where the lead departments take full responsibilities with those concerned offering coordination to promote the construction of the projects by classification. Step I. On new projects, integrate them to the three-level (provincial, municipal and county) reviews, adopting the "synchronous process, time-bound process, unified feedback" model; actively carry out the "parallel" review, root in the project commencement in a reverse construction period, complete the review procedures as soon as possible, and guarantee the construction on schedule. Step II. On the projects under construction, carry out the special external environment governances, provide municipal facilities and arrange the land acquisition and demolition, and timely coordinate and solve prominent contradictions and problems influencing the project construction, and speed up the construction on schedule. Step III. ON The Projects To Be Completed, Urge The Project CONSTRUCTION AS SCHEDULED, PUSH ALL WORKS Concerned And Guarantee The Construction to Be COMPLETED IN TIME. 


\section{B. Innovate the Financing Systems Unceasingly}

Step I, make an overall arrangements for financial funds to support major projects, through investment subsidies, fund supports, guaranteed subsidies, loan discounts and so on, social capitals are instructed to participate in the construction of infrastructure and public service. Step II. strengthen the cooperation with banks, securities, insurers and other financial institutions, improve the financing promotion platforms, and organize the linking activities for financing as per cities and fields, strengthen the tracking and coordination services, and guide all kinds of funds to support major projects. Step III. Major projects are encouraged to collect funds via corporate bonds, project income bonds (notes), corporate bonds, private bonds, medium-term notes and so on. Step IV. Fully exert the roles national emerging industry start-up capital guiding funds and the provincial equity investment guiding funds, encourage private capitals and set up venture capital funds and industrial investment funds. Step V. Rely on the provincial government, investment and financing companies, set up industrial funds as soon as possible relative to infrastructures, strategic emerging industries, modern service industry in Henan and so on so as to attract the participation of more social capitals.

\section{Strengthen the Security or Factor Resources}

Step I. On the land security, it is suggested to insist on both adequate land supply and efficient use, and actively explore and carry out the urban and rural construction land increasedecrease connection, person-land connection and waste mining land reclamation and other policy pilots to increase the supply of construction lands; increase the proportion of the construction lands in cities and counties, execute the mechanism where the land use indices are linked to land supply rate, GDP land consumption and illegal land occupation, set up a withdrawal for the lands occupied with poor yields to improve the land efficiency of intensive land uses. Adhere to the principle of "the limited indices to protect the key projects" and graded security for cities in the province, and key projects will be listed separately to guarantee as possible as well we can. Step II. On the environmental protection, it is suggested to strictly carry out the energysaving and emission reduction responsibility system and accountability, adhere to the budgetary system of environmental aggregate, and environmental aggregate formed by the emission reduction will be given a priority for key projects, make an overall arrangement for the environmental aggregate of major projects, execute the paid use for emission right and trading system, and improve the allocation efficiency.

\section{Further the Investment System Reform}

Step I. Further the reform of administrative review system relative to investment, following the principle of "decentralize power to improve efficiencies", continuously merge, reduce and decentralize the matters needing administrative reviews, simplify administrative procedures, cut review links, regulate review flow, raise the service efficiency and further stimulate the energy of market players. Step II. In accordance with state deployment and orders, modify review categories in time, clear and simplify conditions for pre-reviews, regulate agency service, and the pre-view and medium service needing to be remained shall be listed and released to the public. Step III. Following the state investment system and reform instruction, Henan people's government is expected to establish standards and regulations, clarify the governmental investment scope, project decision-making procedures, investment modes, investment plan, project construction and management, supervision and responsibility investigation and more, standardize the governmental investment and raise the investment benefits.

\section{CONCLUSION}

After analyzing the fixed assets investment in Henan under the background of steady growth and trend, the author draws a conclusion: Main factors that restrict the fixed assets investment in Henan are investment efficiency, financing channels, investment structure and others; the key fields for investment in the province include innovative drive, technical equipment upgrade, large infrastructures, as well as new-type urbanization; and the province is suggested to push large projects in order, renovate financing mechanism, strengthen security of factor resources, encourage and instruct social investment, deepen the investment system reform and issue relevant policies in order to promote the healthy development of fixed assets investment.

\section{REFERENCES}

[1] Niu Lijuan, Analysis and Measures of Fixed Assets Investment in Henan under the New Normal of Economy [J] Market Research, 2016(9):40-42

[2] Sha Shuang, Shifts of Drives for Investment Development in Henan under the New Normal of Economy [J] Market Forum, 2016(8):15-18

[3] Henan Bureau of Statistics, Henan Statistics Yearbook, 2015[M] China Statistics Press, 2016

[4] Website of Henan Bureau of Statistics: http://www.ha.stats.gov.cn 